\title{
Looking for a standardized approach in the surgical treatment of hyperhidrosis
}

\author{
Dania Nachira $^{1} \cdot$ Marco Chiappetta $^{1} \cdot$ Maria Giovanna Mastromarino $^{1} \cdot$ \\ Maria Teresa Congedo ${ }^{1}$ Maria Letizia Vita ${ }^{1}$ Venanzio Porziella ${ }^{1}$.

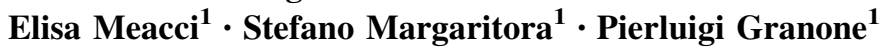

Received: 22 June 2015/ Accepted: 29 June 2015/Published online: 29 September 2015

(C) Springer-Verlag Berlin Heidelberg 2015

We read with great interest the article by Hida et al. [1] reporting on comparison between postoperative effects of sympathotomy by cutting or clamping at T3 on palmar sweating, compensatory sweating, and also on patient satisfaction.

Large series have shown a high success rate after endoscopic thoracic sympathectomy (ETS) [2, 3], with improvement in quality of life of patients, but all these results are hardly comparable due to heterogeneous patient populations, different surgical procedures, and more importantly, the variety of qualitative/quantitative scales for definition of symptoms, results and side effects such as compensatory hyperhidrosis.

Accordingly, we wish to submit our reflections to the attention of the authors and the community to state the importance of using standardized preoperative and postoperative questionnaires to objectify the improvements of these patients.

In the study by Hida et al. [1], the authors proposed the use of two different scales to grade postoperative palmar sweating and patients' satisfaction.

However, recently, the Society of Thoracic Surgeons through Cerfolio and co-workers [4] recommended the use of standardized questionnaires and proposed an example of a data collection sheet that was formulated by De Campos and associates [5]. In the expert consensus, it had also been established that the ETS is the treatment of choice for patients with hyperhidrosis, and that the interruption of the sympathetic chain can be achieved by cauterizing, cutting, or

Dania Nachira

danynac@libero.it

1 Department of General Thoracic Surgery, Catholic University, Rome, Italy clipping but the use of a rib-oriented nomenclature is required because of anatomical variations in the position of ganglia.

In our practice, we are successfully using a version of De Campos' questionnaire partially implemented by us that is administered to patients preoperatively, postoperatively, and at 1 month, 6 months, and 1 year after surgery, as recommended by the expert consensus [4].

However, long-term follow-up studies providing repeated and standardized questionnaires are needed for systematic assessments of patients' symptoms and quality of life, before and after surgery, to help us develop a common evidence-based clinical practice.

\section{Compliance with ethical standards}

Conflict of interest The authors declared that they have no competing interest.

\section{References}

1. Hida K, Sakai T, Hayashi M, Tamagawa T, Abe Y (2015) Sympathotomy for palmar hyperhidrosis: the cutting versus clamping methods. Clin Auton Res. 2015 May 14. (Epub ahead of print) PMID: 25971626

2. Ahn SS, Wieslander CK, Ro KM (2000) Current developments in thoracoscopic sympathectomy. Ann Vasc Surg 14:415-420

3. Kauffman P, Werebe Ede C, Andrade Filho LO, Kusniek S, Wolosker N, Jatene FB, De Campos JR (2013) Quality of life, before and after thoracic sympathectomy : report on 378 operated patients. Ann Thorac Surg 76:886-891

4. Cerfolio RJ, de Campos JR, Bryant AS, Connery CP, Miller DL, DeCamp MM, McKenna RJ, Krasna MJ (2011) The society of thoracic surgeons expert consensus for the surgical treatment of hyperhidrosis. Ann Thorac Surg 91:1642-1648

5. De Campos JR, Kauffman P, Werebe EC et al (2003) Quality of life, before and after thoracic sympathectomy: report on 378 operated patients. Ann Thorac Surg 76:886-891 